\title{
A re-audit of ECT training and practice
}

\author{
Farida Yousaf, Martin Lee and Jose King
}

\begin{abstract}
Aims and methods A re-audit of the current practice of electroconvulsive therapy (ECD) was carried out over a period of five months using the new guidelines produced by the Royal College of Psychiatrists. The areas audited included obtaining consent from the patients, information recording, training and supervision of the junior doctors and the practical aspects of ECT administration, including dose titration.

Results An improvement in the training and supervision of junior doctors was seen since the last audit but shortcomings were identified in areas of pre- and postECT preparation, information recording and correct use of stimulus-dosing policy.

Clinical implications Recommendations include the need to improve clinical practice and recording of information.
\end{abstract}

The Royal College of Psychiatrists has put great emphasis on the current practice of electroconvulsive therapy (ECT) in recent years. Three large-scale audits have been conducted (Pippard \& Ellam, 1981; Pippard, 1992; Duffett \& Lelliott. 1998) and a new set of guidelines has been produced (Royal College of Psychiatrists, 1995). with recommendations on conducting audit locally. In view of the above, we set out to undertake a simple re-audit of the current practice of ECT using the new guidelines at Chiltern Wing, Sutton Hospital. This is a mental health unit providing services to the London Borough of Sutton, staffed by four general consultant psychiatrists, a consultant for old age psychiatry, a rehabilitation psychiatrist and six senior house officers/registrars. A previous audit carried out at the same unit had prompted immediate action, with improvements in several areas including decoration and comfort of the waiting room, training and supervision of junior doctors, giving information to patients for the purpose of obtaining consent and abandoning the routine administration of atropine (HillSmith \& Lee, 1992).

In the second audit an attempt was made to see if those improvements were sustained. although it was not possible to achieve the full audit cycle because of the new guidelines. This coincided with the arrival of a new set of junior doctors and the acquisition of a new ECT machine (Thymatron-DGx) with electroencephalogram (EEG) monitoring.

\section{The study}

Training was given to the junior doctors during the first month in their post using the stimulusdosing schedule with EEG monitoring. This included two hours of training on the practical and theoretical aspects of ECT administration, as well as demonstration and supervision of treatment sessions on the new machine. The audit was started thereafter and was carried out over a period of five months. All the staff, including psychiatric ward nurses, ECT nurse, anaesthetist, junior doctors and consultant psychiatrists, were made aware of the audit at the outset. Only those patients were included for whom new treatment forms were completed. The following check-lists were used:

(a) Consent form.

(b) The ECT treatment record form.

(c) Clinical outcome.

(d) Nursing check-list for ECT patients.

(e) ECT postoperative nursing observations.

(f) Feedback from patients about information/ explanation given to them before starting the treatment.

(g) Questionnaire completed by trainees on the training and supervision.

The first five check-lists were taken from The ECT Handbook (Royal College of Psychiatrists, 1995). Slight modifications were made on the ECT treatment form to provide more space for comments on the treatment session, for review by the team and for the care plan for the next session. For the purpose of describing results, the ECT treatment form was divided into two parts. The first part comprises the section that includes information on the patient, such as diagnosis, indications for ECT, medications, allergies, physical examination, investigations and legal status. The second part gives information about the actual treatment sessions. The last two check-lists were designed and administered by one of the authors (F.Y.), who otherwise 
had no involvement in the training and administration of ECT.

The nursing check-list for ECT patients and the ECT postoperative nursing observations were monitored for the first two months only. A questionnaire to obtain feedback from patients was given/sent to every patient after completion of treatment, along with an explanation or a covering letter.

\section{Findings}

The total number of patients who received ECT during the audit period was 10: one patient received two courses of treatments, hence the total number of courses was 11 .

The only patient to complete the patient questionnaire (who was approached by one of the authors (F.Y.) while still on the ward), had no memory of discussing the treatment prior to receiving it. Results on training and supervision were obtained from all six junior doctors. All the doctors had seen the ECT being administered and five had received personal supervision by the consultant while administering the treatment. All six doctors felt that continuing supervision was available to them to ensure that clinical practice kept pace with research.

The nursing check-list and ECT postoperative nursing observations were recorded appropriately for the first two months of the study only.

The first part of the ECT treatment record form was completed in all cases where applicable, except for one where the relevant sheet was missing from the case notes. While looking at the information recorded during the treatment sessions, we focused on the ECT administration technique. The starting dose was not adjusted according to the patient's age in six cases out of ten that were above 65 . Initial dose gave an adequate seizure in seven treatment courses $(64 \%)$. For the remaining four, correct titration steps were taken only in half of the cases. Incorrect suprathreshold stimulation was given during six courses (55\%). Dosage was increased correctly during only one out of 10 courses, whereas for the remaining one this was not required. No clinical outcomes were recorded at all in the appropriate section of the treatment form.

\section{Comment}

Failure to use the stimulus-dosing policy correctly, and to record clinical outcome at regular intervals as recommended by the College, is disappointing but partly reflects the early stages of learning a new technique and using a new prescription and monitoring form. Problems in the implementation of ECT guidelines have also been reported by Duffett \& Lelliott (1998) in their third large-scale audit covering 184 ECT clinics in England and Wales. They rated only one-third of clinics as meeting College standards and concluded that 20 years of activity by the College and three large-scale audits have been associated with only modest improvement in local practice.

The nursing staff were unable to commit themselves to the audit for the full period because of their already busy schedule. However, failure to prepare safely the patient prior to treatment or observe postoperatively could be regarded as dangerous, and failure to record these nursing procedures could be regarded as negligent. The structured recording of clinical information remains a challenge for us all, but can be seen as a burden additional to the need to keep informal progress notes in the patient's clinical files.

The poor feedback response from the patients could have been improved by checking with them, while still in-patients, the information and explanation that they had received before the ECT course began. The failure of our trainees to adjust the starting dose for age, use the correct dosing steps and ensure that the treatment dose was given one step higher than the seizure threshold can be explained by the fact that they had not used the technique before, but must also reflect a failure of the teaching and supervision provided by the consultant psychiatrist (M.L.). However, it was encouraging to find that the feedback from trainees, on the training provided, showed a marked improvement compared with our first audit.

\section{Recommendations}

The audit cycle defines standards, checks practice against standards, adjusts practice and re-audits. Our second audit has shown that introducing a more complex ECT technique, with more rigorous recording of information, is not easy. The key recommendations are as follows:

(a) The ECT record form suggested by The Royal College of Psychiatrists in The ECT Handbook requires minor adjustments to facilitate recording and prescription of treatment.

(b) Nursing staff need encouragement to monitor and record their tasks in the pre-ECT preparation and post-ECT recovery of the patient, to ensure safe practice.

(c) Patients' understanding of the information given about ECT should be checked each week during the treatment course. Written information should be provided routinely.

(d) There should be greater emphasis on training and supervision, concerning the 
rationale for the dosage steps, when using a dosing schedule (this has been included already in subsequent training in the unit).

(e) Clinical outcome should be recorded at least once, clearly, on the in-patient discharge summary.

Psychiatrists still need to be challenged to introduce modern ECT machines, using EEG monitors and dosing schedules to maximise treatment and minimise side-effects.

\section{References}

DUFFeTT, R. \& LELUOT, P. (1998) Auditing electroconvulsive therapy. The third cycle. British Journal of Psychiatry. 172, 401-405.

HILL-SMITH, A. J. \& LEE, M. S. (1992) ECT - current practical administration. Psychiatric Bulletin, 16 269-271.
PIPPARD, J. (1992) Audit of electroconvulsive treatment in two national health service regions. British Journal of Psychiatry, 160. 621-631.

- \& ELLAM, L. (1981) Electroconvulsive treatment in Great Britain: a report to the College. British Journal of Psychiatry, 139, 563-568.

ROYAL COLLEGE OF PSYCHIATRISTS (1995) The ECT Handbook: the Second Report of the Royal College of Psychiatrists. Special Committee on ECT. Council Report CR39. London: Royal College of Psychiatrists.

Farida Yousaf, Consultant Psychiatrist, Surrey Oaklands NHS Trust, 23 High Street, Leatherhead, Surrey KT22 8AB; Martin Lee, Consultant Psychiatrist, St Helier NHS Trust, 36-38 High Street, Carshalton. Surrey SM5 3AG; and *Jose King, Research Psychologist, Henderson Hospital, 2 Homeland Drive, Brighton Road, Sutton, Surrey SM2 5LT

*Correspondence

\title{
Multi-disciplinary assessment of attention-deficit hyperactivity disorder: a tertiary assessment package
}

\author{
H. Kat, Clay Frake and Rebecca Sawtell
}

\begin{abstract}
Aims and method A tertiary assessment package was set up for the more equivocal cases of attention-deficit hyperactivity disorder (ADHD) who present with problems of inattention, impulsivity and overactivity. The structure of the three-day package was discussed. with an analysis of our experience in assessing 12 children using the pilot project. The package and its use in clinical practice are presented.

Results The pilot project described can be modified into a two-day package.

Clinical implications Assessment of ADHD conducted in multiple settings inherently has many advantages over single clinic assessment. We suggest that such an assessment protocol can be conducted cost effectively.
\end{abstract}

The Tanglewood Children's Day Resource Centre in Leicester provides a tertiary service to the Leicestershire Child and Family Psychiatric service and routinely runs extended assessment packages as part of its programme for children under the age of 12 years (Davison, 1996). Towards the end of 1996, there was a clear increase in the number of referrals from general practitioners with concerns regarding the diagnosis of attention-deficit hyperactivity disorder (ADHD) in Leicester. The trend coincided with growing public awareness of the disorder and its attendant media profile (a search for "attention deficit disorder" on the internet using the Lycos search engine yielded 